Discussion Paper No. 08-040

\title{
Asymmetric Price Transmission in Supply Function Equilibrium, Carbon Prices and the German Electricity Spot Market
}

Nikolas Wölfing

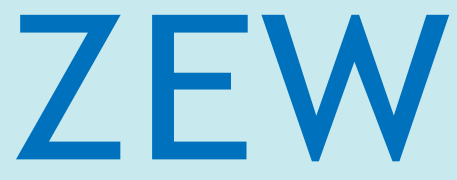

Zentrum für Europäische Wirtschaftsforschung $\mathrm{GmbH}$

Centre for European

Economic Research 
Discussion Paper No. 08-040

\title{
Asymmetric Price Transmission in Supply Function Equilibrium, Carbon Prices and the German Electricity Spot Market
}

\author{
Nikolas Wölfing
}

Download this ZEW Discussion Paper from our ftp server:

ftp://ftp.zew.de/pub/zew-docs/dp/dp08040.pdf

Die Discussion Papers dienen einer möglichst schnellen Verbreitung von neueren Forschungsarbeiten des ZEW. Die Beiträge liegen in alleiniger Verantwortung der Autoren und stellen nicht notwendigerweise die Meinung des ZEW dar.

Discussion Papers are intended to make results of ZEW research promptly available to other economists in order to encourage discussion and suggestions for revisions. The authors are solely responsible for the contents which do not necessarily represent the opinion of the ZEW. 


\section{Non-technical summary}

The purpose of this paper is to explore the behavioural background for an asymmetric pass-through of input prices at a power spot market. G. Zachmann and C. von Hirschhausen report empirical evidence for such an asymmetric effect of $\mathrm{EU} \mathrm{CO}_{2}$ emission allowance prices on German electricity spot prices at the European Energy Exchange in Leipzig (EEX). Increasing carbon prices were followed by significant increases in power spot prices. Decreasing carbon prices, however, showed smaller and less significant inverse effects on power prices. The empirical study of Zachmann et al. provides no explanation for the reason of such an asymmetric reaction. The following article attempts to shed light on this open question.

Usual results of microeconomic theory suggest that a cost shock should be passed through symmetrically, no matter if the market is monopolistic, oligopolistic or in perfect competition. Theoretical explanations for asymmetric price responses to external shocks in various markets mostly considered specific circumstances, such as search costs, menu costs or specific stock adjustment policies. At power spot markets, however, there are no stocks, no search or menu costs or any other relevant frictions. Firms compete by submitting supply functions and the price is fixed by the auctioneer. Thus, asymmetric price reactions must be due to asymmetric adjustments of the submitted functions. At EEX, these individual bids are not reported and strictly confidential. My argument to explain the asymmetric pass-through of emission allowance prices is that firms use the price signal as a coordinating mechanism. Through coordinated action, firms might increase their joint profits, but since cooperation among firms is illegal, coordination should work tacitly. An asymmetric transmission of input prices permits to jointly tighten the offer and thus to increase prices slightly and stepwise over time. Specific features of carbon prices qualify them best as an instrument for collusion: carbon prices are fluctuating and exactly determined every day. Moreover, emission allowances are an input to all fossil fuel fired plants (gas or coal), who typically determine the electricity spot price as the marginal plant. Another important point is about timing: emissions trading started in 2005. This gives a natural focal point for firms at what date the coordination of bids should start, and thus reduces the need for communication.

The following article explores the incentive structure of such a coordinating mechanism in a stylised model of a spot market where two symmetric firms compete in supply functions. The results show, that firms under this setting always have an incentive to collude by asymmetrically submitting input cost shocks when they start from non-cooperation. 


\section{Das Wichtigste in Kürze}

Die vorliegende Arbeit sucht nach einer Erklärung für eine asymmetrische Kostenweitergabe von Input-Preisen an einer Strombörse. G. Zachmann und C. v. Hirschhausen [2008], konnten zeigen, dass EU-Emissionszertifikatspreise einen asymmetrischen Einfluss auf die Stromspotpreise an der European Energy Exchange (EEX) in Leipzig hatten. Steigende Preise für $\mathrm{CO}_{2}$ Emissionszertifikate führten zu einem signifikanten Anstieg der Strompreise im Spotmarkt, während sinkende $\mathrm{CO}_{2}$ Preise einen geringeren und weniger signifikanten Einfluss zeigten. Die empirische Studie zeigt jedoch keinerlei Erklärung für dieses Phänomen auf.

In gängigen mikroökonomischen Marktmodellen erzeugen Kostenfluktuationen eine symmetrische Preisreaktion, so dass nach einer Auf- und einer gleichgroßen Abwärtsbewegung der Ausgangszustand wieder erreicht wird. Modelle die eine asymmetrische Preisreaktion ergeben, stützen sich meist auf spezielle Umstände, wie Suchkosten für Konsumenten, Preisanpassungskosten oder spezielle Lagerhaltung. Keiner dieser Einflüsse ist an einer Strombörse wie der EEX gegeben. Gebote werden hier als Preis-Mengen-Kombinationen abgegeben welche eine individuelle Angebotsfunktion beschreiben. Der Preis wird vom Auktionator bestimmt, daher muss sich eine asymmetrische Kostenweitergabe bereits in den Gebotsfunktionen niederschlagen. Diese Gebotsfunktionen unterliegen an der EEX strikter Geheimhaltung. Der folgende Artikel sieht den Grund für die asymmetrische Preisweitergabe darin, dass die Anbieter im Strommarkt mithilfe des externen Preissignals vom $\mathrm{CO}_{2}$ Markt ihre Gebote koordinieren. Durch ein koordiniertes Bietverhalten könnten alle Firmen ihre Profite vergrößern. Um dem Kartellverbot zu entgehen, müsste die Abstimmung der Gebote schweigend vor sich gehen. Eine asymmetrische Einpreisung von Kostenfluktuationen ermöglicht es, dass alle Firmen gleichzeitig ihre Mengengebote verknappen, und damit über die Zeit gestreckt schrittweise höhere Preise erzielen. $\mathrm{CO}_{2}$ Preise weisen für diese Form der Koordination einige wichtige Eigenschaften auf: das Preissignal ist eindeutig und täglich bestimmt. $\mathrm{CO}_{2}$ Emissionszertifikate sind für alle fossil befeuerten Kraftwerke ein Kostenfaktor, und die preissetzenden Kraftwerke im Spotmarkt sind meist Kohle oder Gaskraftwerke. Der Emissionshandel hat einen eindeutigen Startpunkt in 2005. Der Beginn des Emissionshandels bietet damit einen klar definierten Startzeitpunkt für die asymmetrische Weitergabe der Kostenfluktuationen.

Der folgende Artikel untersucht die Anreizstruktur einer solchen Form der Koordination im Rahmen eines stilisierten Stromspotmarktes auf dem Gebote als Angebotsfunktionen abgegeben werden. Das Ergebnis im Rahmen des Models zeigt, dass die beteiligten Firmen es im Ausgangsgleichgewicht immer vorziehen zu kooperieren. 


\title{
Asymmetric Price Transmission in Supply Function Equilibrium,
}

\section{Carbon Prices and the German Electricity Spot Market}

\author{
Nikolas Wölfing* \\ Centre for European Economic Research $(\mathrm{ZEW})^{\dagger}$
}

June 2008

\author{
JEL classification: C73, D82, L13, Q41 \\ Key words: Asymmetric price transmission, \\ Electricity spot markets, \\ Emission allowances.
}

\begin{abstract}
In January 2007, first evidence of an asymmetric pass-through of $\mathrm{CO}_{2}$ emission allowance prices was reported for the German electricity spot market. This paper explores the theoretical basis for such an asymmetry in the context of a supply function bidding duopoly. It interprets fluctuating carbon prices as a coordination mechanism for tacitly colluding firms and studies incentive compatibility in the repeated game. It is new in its attempt to model asymmetric behaviour in a spot market without relevant frictions, and gives a reasoning why the asymmetry shows up for emission allowances only. The paper concludes with a theorem: that asymmetric price transmission is sustained up to a certain maximum level which might include the monopoly solution and that this mechanism is always preferred to non-cooperation.
\end{abstract}

\footnotetext{
*Contact: phone (+49)-621-1235-217, fax (+49)-621-1235-226, woelfing@zew.de.

${ }^{\dagger}$ Address: L7, 1, 68161 Mannheim, Germany
} 



\section{Introduction}

Following its deregulation in 1998, the German market for electricity generation has seen a wave of mergers leading to a four-firm oligopoly with two dominant firms [Bundeskartellamt, 2006]. In 2001, a wholesale spot market for power was established at the European Energy Exchange (EEX) in Leipzig. The market operates as a daily one-shot auction, in which electricity generators have to submit stepwise linear and non-decreasing supply functions, specifying the quantities they are willing to supply at each price, while buyers have to submit stepwise linear and non-increasing demand functions which specify the quantities they are willing to buy at each price. Aggregating the submitted demand and supply functions, the auctioneer chooses a market clearing equilibrium price at which trades are executed according to the submitted bids.

In 2005, the European Union introduced the EU Emission Trading Scheme (EU ETS) which caps the total amount of $\mathrm{CO}_{2}$ emissions for several industries but allows to trade the (freely distributed) emission allowances (EUA) among regulated firms. Since then, the prices of EUA reflect an opportunity cost for the generation of electricity with fossil fuel fired plants. The price for electricity in the power spot market is determined by the marginal plant, and these plants are mostly gas or coal-fired. Hence, according to economic theory one would expect that an increase in the price of EUA would lead to an increase in the wholesale prices of electricity, while a decrease in the price of EUA would lead to a decrease in the wholesale prices of electricity. Indeed, following the introduction of the EU ETS, both the spot and future wholesale prices for power quite closely followed the increase in EUA prices, which peaked in April 2006. In May 2006, the carbon market crashed and EUA prices dropped from almost $€ 30$ per ton of $\mathrm{CO}_{2}$ to less than $€ 10$ per ton and continued to decrease to $€ 0.80$ per ton in February 2007. However, this steep price decline has not yet led to a corresponding drop in the wholesale price of electricity at EEX. Zachman and Hirschhausen [Zachmann and von Hirschhausen, 2008] find strong empirical evidence of an asymmetric effect of EUA prices on power prices at EEX, but they do not provide a theoretical explanation. This is where my paper attempts to shed light on.

Similar phenomena have been observed in various markets. Peltzman [Peltzman, 2000] reports asymmetric transmission of input prices for a large number of products mainly in the food sector, and states that this "points to a serious gap in a fundamental area of economic theory". The most prominent example of asymmetric price responses is the US gasoline market of the early 1990s. Increasing crude oil prices caused sky-rocketing gasoline prices, but the 
inverse relation did not hold true ${ }^{1}$. The pattern can be very well explained by search costs, preventing consumers to search further when they observe falling prices (see e.g. [Lewis, 2001]). Suppliers then profit from less elastic demand and keep prices relatively high. In a power spot market, however, there are no search costs, neither are there any menu costs, inventories or institutions which might relate to downward rigidity. The reason for the asymmetry must be the strategic behaviour of market participants. However, a theoretical analysis of the actors interest in asymmetric rigidity is missing.

The following article argues that EUA prices are used as a coordinating signal for collusively bidding generators. The argument can intuitively explain why the asymmetry shows up for carbon price effects only. A stylised theoretical analysis shows that collusion is always preferred to non-cooperation. The outline is as follows: In section 2, I will introduce a stylised model of competition in supply functions. Section 3 explores the interest of firms to coordinate and interprets carbon prices as an appropriate instrument to do so tacitly. Section 4 studies the incentive structure of the repeated game and section 5 concludes.

\section{The Model}

Competition in supply functions is quite difficult to analyse due to mathematical complexity and a possible multitude of equilibria. The seminal work on the subject is due to Klemperer and Meyer [Klemperer and Meyer, 1989]. However, power spot market designs often impose supply function bidding, because it provides the necessary flexibility to meet fluctuating demand. Applications of the theory therefore focused on electricity markets.

To model competition in supply functions, the linear approach has proven to be quite useful in providing a unique equilibrium and nevertheless being an interesting representation for empirically motivated studies [Baldick et al., 2004]. Advancements have been made with numerical implementations, introducing asymmetric firms or allowing supply functions to be stepwise linear, e.g. by [Green, 1996] or [Baldick et al., 2004]. I will restrict my analysis to the symmetric linear duopoly case which has already been solved by Turnbull [Turnbull, 1983], and which is the only one to provide a unique and analytically solvable equilibrium. In detail, linearity assumptions are made for demand, supply, and marginal costs. The following subsection introduces the simple model based on Turnbull, subsequent parts will extend the analysis to cooperation and the repeated game.

\footnotetext{
${ }^{1}$ The literature refers to 'rockets and feathers' because the downward adjustment reminded more of the decline of a dwindling feather, see e.g. [Borenstein et al., 1997].
} 


\section{A basic model of supply function equilibrium}

Let $i$ and $j$ be two symmetric firms, producing quantities $q_{i}, q_{j}$ at $\operatorname{cost} C(q)$.

$$
C(q)=\frac{c}{2} q^{2} \quad c>0
$$

The cost parameter $c$ can be seen as an aggregate of carbon prices and other production costs: for instance let $p_{e}$ be the price for emission allowances needed for the first produced quantity of output $q$. Assume emission intensity to increase along the expansion path, such that the effect can be approximated by a quadratic relation. The costs of emissions are then given by $p_{e} \cdot q^{2}$. In this scenario, carbon price fluctuations have a linear effect on the general cost parameter c.

Firms compete by submitting linear supply functions $q(p)=\beta \cdot p$. A strategy of firm $i$ is a supply function $q_{i}(p)$ which is completely identified by the slope parameter $\beta_{i}>0$. The auctioneer determines the equilibrium price $p^{*}>0$ such that aggregate produced quantity $q_{i}\left(p^{*}\right)+q_{j}\left(p^{*}\right)$ equals demand $D\left(p^{*}\right)$. The functional forms of demand, the market clearing equilibrium price and $\Pi^{i}$, the profit of firm $i$, are as follows:

$$
\begin{aligned}
D(p) & =\tilde{N}-\gamma p & \tilde{N}, \gamma \geq 0 \\
p^{*} & =\frac{\tilde{N}}{\gamma+\beta_{i}+\beta_{j}} & \\
\Pi^{i} & =p q_{i}-C\left(q_{i}\right) & \\
\Pi^{i}\left(\beta_{i}, \beta_{j}\right) & =\left(\frac{\tilde{N}}{\gamma+\beta_{j}+\beta_{i}}\right)^{2}\left(\beta_{i}-\frac{c}{2} \beta_{i}^{2}\right) &
\end{aligned}
$$

Demand fluctuations are covered by $\tilde{N}$, a positive random variable whose realisation is not known in advance ${ }^{2}$. Firm $i$ then maximises its profit for each $N$ over its residual demand $q_{i}=D(p)-q_{j}(p)$.

$$
\max \left[\Pi^{i}\right]=p \cdot\left[D(p)-q_{j}(p)\right]-C\left(\left[D(p)-q_{j}(p)\right]\right)
$$

\footnotetext{
${ }^{2}$ This model can fully represent the more general model with affine supply functions $s(p)=$ $\alpha+\beta p$ and costs $K(q)=c_{0}+c_{1} p+c_{2} p^{2}$ as has been shown, for instance, by Baldick et al. [Baldick et al., 2004]: firms will always choose the intercept of the inverse supply function to equal the intercept of marginal cost. When firms are symmetric, arguing in prices net of the marginal cost intercept therefore allows to reduce the model without loss of generality to the linear version as it is presented here.
} 
The first order condition is

$$
\begin{aligned}
\frac{\partial \Pi^{i}}{\partial p} & =\left[D(p)-q_{j}(p)\right]+\left[D^{\prime}(p)-q_{j}^{\prime}(p)\right] \cdot\left[p-C^{\prime}\right] & & =0 \\
& =q_{i}-\left(\gamma+\beta_{j}\right)\left(p-c q_{i}\right) & & =0 \\
\Rightarrow \beta_{i} & =\left(\gamma+\beta_{j}\right)-c \beta_{i}\left(\gamma+\beta_{j}\right) & &
\end{aligned}
$$

The last equation imposes a general condition on the strategic parameters $\beta_{i}$ and $\beta_{j}$, which does not depend on price or the random variable $\tilde{N}$. This illustrates a central feature of SFE models; firms choose an optimal supply schedule for every possible realisation of demand [Klemperer and Meyer, 1989]. Solving for $\beta_{i}$ yields a candidate for the best response function, which I will denote $B R\left(\beta_{j}\right)$.

$$
\beta_{i}=B R\left(\beta_{j}\right) \equiv \frac{\left(\gamma+\beta_{j}\right)}{1+c\left(\gamma+\beta_{j}\right)}
$$

The second order condition for profit maximisation holds for $\beta_{i}=B R\left(\beta_{j}\right)$ and is checked in appendix A.1. This establishes $B R\left(\beta_{j}\right)$ as the best response function for firm $i$. Indeed, the necessary and sufficient conditions are fulfilled at one and only one point given by the best response defined in (2). Therefore, $\Pi^{i}\left(\beta_{i}, \beta_{j}\right)$ increases with $\beta_{i}$ for all $\beta_{i} \in\left[0, B R\left(\beta_{j}\right)\right]$ and decreases for all $\beta_{i}>$ $B R\left(\beta_{j}\right)$. This property is needed for further discussion.

PROPERTY 1.

$$
\frac{\partial \Pi_{i}\left(\beta_{i}, \beta_{j}\right)}{\partial \beta_{i}}= \begin{cases}>0 & \text { if } \beta_{i} \in\left[0, B R\left(\beta_{j}\right)[\right. \\ =0 & \text { if } \beta_{i}=B R\left(\beta_{j}\right) \\ <0 & \text { if } \beta>B R\left(\beta_{j}\right)\end{cases}
$$

Considering $B R($.$) , one can check for a Nash equilibrium. The best response$ function has some interesting features which are given below.

$$
\begin{aligned}
\lim _{\beta_{j} \rightarrow \infty} B R\left(\beta_{j}\right) & =\frac{1}{c} \\
\lim _{\beta_{j} \rightarrow 0} B R\left(\beta_{j}\right) & =\frac{1}{\frac{1}{\gamma}+c} \\
0<B R^{\prime}\left(\beta_{j}\right) & =\frac{1}{\left(1+c\left(\gamma+\beta_{j}\right)\right)^{2}}<1 .
\end{aligned}
$$

Note that the upper bound of the best response $1 / c$ corresponds to the marginal cost bid or Bertrand bid. Any strategy $\beta<1 / c$ defines a less competitive bid. 
The lower bound $\gamma /(1+c \gamma)$ corresponds to the trace through all Cournot bids in a market with the given demand and cost functions. A supply function equilibrium (SFE) therefore lies in between these both. From the derivative of the best response we can see that the slope parameters $\beta_{i}$ and $\beta_{j}$ are strategic complements and that the nested best response function constitutes a contraction map. In other words: an increase of $\beta_{j}$ also increases $i$ 's best response, but with lower magnitude and vice versa. Thus, no matter what the initial level of $\beta_{j}$ is, an iteration of mutual best responses necessarily converges to an equilibrium in the interval between Cournot and Bertrand strategies.

Solving for the symmetric best response, such that $\beta=B R(\beta)$, yields only one positive solution, which is the unique supply function equilibrium in noncooperative strategies: $\left(\beta_{S F E}, \beta_{S F E}\right)$.

$$
\beta_{S F E} \equiv \frac{\sqrt{\gamma^{2}+\frac{4 \gamma}{c}}-\gamma}{2}
$$

\section{Joint profit maximisation}

The Nash equilibrium established above is the solution to the non-cooperative one-shot game. Assuming that cooperative strategies are feasible, firms might do better by coordinating their bids and thus maximising joint profits. Coordination is of interest if joint profit maximisation outperforms the profits of the non-cooperative equilibrium. The cooperative programme for two symmetric firms is

$$
\max _{\beta}[2 \Pi(\beta, \beta)]
$$

FOC:

$$
\begin{aligned}
\frac{\partial 2 \Pi(\beta, \beta)}{\partial \beta} & =2\left[\left(2 \cdot \frac{-2 N^{2}}{(\gamma+2 \beta)^{3}}\right) \cdot\left(\beta-\frac{c}{2} \beta^{2}\right)+\left(\frac{N^{2}}{(\gamma+2 \beta)^{2}}\right) \cdot(1-c \beta)\right] & =0 \\
& \Leftrightarrow-4\left(\beta-\frac{c}{2} \beta^{2}\right)+(2 \beta+\gamma)(1-c \beta) & =0
\end{aligned}
$$

which solves to,

$$
\beta=\beta_{c o l} \equiv \frac{\gamma}{2+c \gamma} .
$$

Joint profit maximisation over the same set of strategies $\left(\beta_{i}, \beta_{j}\right) \in \mathbb{R}_{+}^{2}$ yields a different optimal strategy compared to the non-cooperative equilibrium $\beta_{c o l}<$ $\beta_{S F E}$. This implies that cooperation pays: $\Pi^{i}\left(\beta_{c o l}, \beta_{c o l}\right) \geq \Pi\left(\beta_{S F E}, \beta_{S F E}\right)$. The 
local second order condition holds as well, and is checked in appendix A.2. As there is a unique maximum, we can say that profits increase for joint variation of $\beta$ in $\left[0, \beta_{c o l}\right]$, and decrease beyond $\beta_{c o l}$.

PROPERTY 2.

$$
\frac{\partial \Pi_{i}(\beta, \beta)}{\partial \beta}= \begin{cases}>0 & \text { if } \beta \in\left[0, \beta_{c o l}[\right. \\ =0 & \text { if } \beta=\beta_{c o l} \\ <0 & \text { if } \beta>\beta_{c o l} .\end{cases}
$$

Note that the level of $\beta_{c o l}$ is even below the Cournot schedule given by $\frac{\gamma}{1+\gamma c}$. At this stage, it might be worthwhile discussing the relevance of such a quasimonopoly solution. To my knowledge, profit maximisation in supply function equilibria has rarely been studied beyond the Cournot-solution ${ }^{3}$. This is certainly not due to ignorance on the part of the scientific community, but based upon empirical findings: even Cournot models have been accused of exaggerating the exertion of market power due to the highly inelastic demand for electricity [Baldick et al., 2004]. Perfectly collusive, say quasi-monopolistic strategies would result in prices far above the Cournot outcome. My reason to discuss this perfect cartel solution is twofold: first, the result gives a benchmark that shows down to which point capacity withholding is theoretically profitable. Second, because the cooperative strategies exaggerate capacity withholding, it is evident that these strategies are unlikely to describe the current situation and that their implementation would arouse great public indignation. These conclusions are particularly relevant to the study of the repeated game in the next section.

\section{Coordination in the Repeated Game}

Actual power spot markets typically work on a daily basis with the shortest possible lag between market clearance and the time of delivery. While demand might fluctuate, the rules and the participants of the market are quite stable. This corresponds to the setting of a repeated oligopoly game, and should be studied accordingly. For the duopoly case described in section 2, the objective of firm $i$ in the repeated game is to maximise the present value of all future profits. First, define $\hat{\Pi}_{t}^{i}$ as the expected value of $i$ 's profit in period $t$ with respect to the random demand parameter $\tilde{N}$. Time indices for the strategic

\footnotetext{
${ }^{3} \mathrm{An}$ exception is an early paper on SFE in electricity markets by Bolle [Bolle, 1992].
} 
variables are ommitted for simplicity.

$$
\hat{\Pi}_{t}^{i}\left(\beta_{i}, \beta_{j}\right) \equiv \mathbb{E}_{\tilde{N}_{t}}\left[\Pi^{i}\right]=\frac{\mathbb{E}\left[\tilde{N}^{2}\right]}{\left(\gamma+\beta_{i}+\beta_{j}\right)^{2}}\left(\beta_{i}-\frac{c_{t}}{2} \beta_{i}^{2}\right)
$$

This definition is symmetric to the definition of profits in equation (1). Now, let $r$ represent the day-to-day interest rate to discount future profits. The program for intertemporal profit maximisation of firm $i$ in period $t=0$ is

$$
\max \left[\sum_{t=0}^{\infty}\left(\frac{1}{1+r}\right)^{t} \hat{\Pi}_{t}^{i}\left(\beta_{i}, \beta_{j}\right)\right]
$$

Evidently, the one-shot Nash equilibrium $\beta_{i}=\beta_{j}=\beta_{S F E}$ from section (2) is also a solution for the repeated game. However, it is a well known result from economic theory (generally phrased as 'the folk theorem') that in repeated oligopoly games a continuum of collusive outcomes beyond the one-shot Nash strategies might as well be sustained as equilibria by a self-policing cartel. This is because cooperative strategies can be enforced when firms fear punishment in future periods. This is shown for the case of price competition among others by [Tirole, 1988], for Cournot competition by [Green and Porter, 1984]. A comparable result for competition in supply functions will be proved in section 4. An oligopoly engaged in collusion typically earns significantly higher profits, but has to agree on the equilibrium it wants to enforce. Thus, firms have to coordinate.

Let us see to what extent this applies to power spot markets: coordination of strategies might work through overt communication, a tacit agreement or signalling. Overt communication is generally ruled out by law. A natural focal point for tacitly colluding firms is the quasi-monopolistic solution which would be chosen by a perfect cartel. However, as discussed above, the perfect cartel solution for power spot markets is likely to exaggerate price increases far beyond a sustainable level and would therefore immediately trigger governmental action. A smaller level of collusion, however, might be less visible and already greatly increase the firms profits. To realise these profits, firms have to overcome the dilemma of multiple equilibria and uncertainty about the rivals' strategy. Note that the individual bids of firms are not reported. When the market has cleared, each firm learns the equilibrium price, the quantity it sold and the size of the whole market. It therefore can deduce ex-post if the rest of the market bid higher or lower quantities for the same price, but not the slope or shape of other firms supply functions [EEX, 2007]. The lack of visibility hinders coordination of individual bids by direct signalling. Suppose a firm tends to induce collusive bidding through direct signalling: it would risk large losses before rivals could perceive the collusive device. A coordinated simultaneous move of all firms, however, would increase profits for each of the players. 


\section{The role of asymmetric cost transmission}

Suppose that initially all firms bid their non-cooperative one-shot equilibrium strategies $\beta_{S F E}$. If the oligopoly aims at realising collusive profits, suppliers have to agree on 'when?' and 'how much?' they want to simultaneously tighten their supply. Thus, they need a coordinating mechanism, which leads to a simultaneous departure from the one-shot equilibrium. Such a coordination mechanism for the withholding of generation capacity should (a) be tacit for legal reasons, should (b) lead to small but repeated joint variation towards the collusive strategies, should (c) be irregular enough not to be easily recognisable by an outsider but (d) has to be precise and easily interpretable for each firm.

An asymmetric pass-through of input prices might play this role. The slope of the equilibrium supply function $\beta_{S F E}$ decreases in costs ${ }^{4}$. A not fully transmitted downward cost shock will result in an ex-post less competitive bid, incorporating 'historical' or say 'fictive' costs. To describe this formally, let $c_{t} \in[\underline{c}, \bar{c}]$ be the realisation of the fluctuating cost parameter $\tilde{c}_{t}$ in period $t$. Now, define a measure $\Delta_{t}$ of non-transmitted downward cost shocks for each $t \in \mathbb{R}_{+}$.

$$
\Delta_{t} \equiv \begin{cases}0 & \text { if } t=0 \\ \Delta_{t-1} & \text { if } t>0, c_{t} \geq c_{t-1} \\ \Delta_{t-1}+x \cdot\left(c_{t-1}-c_{t}\right), \text { with } x \in[0,1] & \text { if } t>0, c_{t}<c_{t-1}\end{cases}
$$

Firms bidding according to fictive costs $c_{t}+\Delta_{t}$ transmit costs asymmetrically, where the parameter $x$ determines the degree of downward rigidity. $x=0$ implies perfect transmission of all costs shocks, while $x=1$ represents total downward rigidity. In the linear case, such a downward rigid strategy is fully described by the following slope parameter:

$$
\beta_{A P T}\left(\Delta_{t}\right) \equiv \frac{\sqrt{\gamma^{2}+\frac{4 \gamma}{c_{t}+\Delta_{t}}}-\gamma}{2}
$$

Given a starting date $t=0$, the value of $\Delta_{t}$ measures precisely the distance from the non-cooperative equilibrium in each period. No further coordination apart from an initial agreement on $t_{0}$ and $x$ is needed to implement this mechanism. When all firms incorporate the same value of $\Delta_{t}$, no firm has to bear the loss of a unilateral departure from its best response. Therefore, the quality of the external signal $\tilde{c}_{t}$ is essential for the efficiency of this mechanism. $c_{t}$ has to fluctuate continuously with small amplitude and an easily and precisely observable outcome. Emission allowances exactly fulfil this property: they are auctioned daily at EEX just before the power auction takes place, they show continuous

\footnotetext{
${ }^{4}$ See the definition in (3) and its derivative with respect to $c$
} 
price fluctuations, and they are an input to all fossil fuel fired plants, as opposed to gas or coal fired plants each separately. However, the most important point is in the question of initial timing. The coordinating signal is defined in time, and there must be an unambiguous date $t=0$ when the game starts to obtain the symmetry of bids. The commencement of EU ETS provides a natural focal point for the start of the collusive game. No other input but EUA has this property, and this leads to a central argument of my article: the introduction of emissions trading in 2005 provided an unprecedented opportunity for the installed power oligopoly to collude tacitly by an asymmetric pass-through of EUA prices. If this is true, the discreetness of the mechanism has been witnessed by reality. It took two years and an immense crash in the carbon market 2006 to reveal the asymmetry.

\section{The incentive constraint in the repeated game}

If the coordination mechanism described above is to be implemented, one has to study incentive feasibility. From a joint perspective, it is clear that lowering offer curves only pays until the optimal collusive solution $\beta_{c o l}$ is reached. From there on firms will have an interest in transmitting costs symmetrically $(x=0)$, and the oligopoly then acts like a perfect cartel. Define $\Delta_{\max }$ to be the maximum value for $\Delta_{t}$, such that the collusive bid is reached.

$$
\begin{aligned}
\Delta_{\max } & \equiv \arg \left[\Delta \in \mathbb{R}_{+}, \beta_{A P T}(\Delta)=\beta_{c o l}\right] \\
& =\frac{4+c \gamma}{\gamma(3+c \gamma)}
\end{aligned}
$$

As I mentioned above, it is questionable if this level of $\Delta_{t}$ is politically feasible. Here it only gives an upper bound on capacity withholding in the repeated game.

The greater concern is individual incentive feasibility. In short, expected future profits resulting from sustained collusion must exceed profits from cheating and playing the individual best response. Define the deviating strategy as

$$
\beta_{\text {dev }}\left(\Delta_{t}\right)=B R\left(\beta_{A P T}\left(\Delta_{t}\right)\right)
$$

Once cheated, a tricked firm will seek to play its individual best response as well since the collusive agreement has been broken. By repeated anticipation of each other's best responses, both firms will go straight back to their one-shot equilibrium strategies $\beta_{S F E}$. Lacking a new starting point for coordination, firms cannot do better than playing the one-shot equilibrium for all following periods. This results in what is usually called a grim strategy. So the structure of the repeated game is as follows: starting at $t=0, \Delta_{t}=0$, firms bid the asymmetrically adjusting strategies $\beta_{A P T}$. When a firm deviates, it plays its 
best response according to (10). After collusion has broken, both firms are back at the non-cooperative equilibrium for all following periods. If the perfect cartel situation with $\Delta_{t}=\Delta_{\max }$ is reached before collusion breaks, firms will jointly bid like a perfect cartel.

The resulting incentive constraint for sustained collusion in period $\tau$ is

$$
\mathbb{E}_{\tilde{c}_{t}}\left[\sum_{t=\tau}^{\infty} \frac{\hat{\Pi}_{A P T}\left(\Delta_{t}\right)}{(1+r)^{t-\tau}}\right] \geq \mathbb{E}_{\tilde{c}_{t}}\left[\hat{\Pi}_{d e v}\left(\Delta_{\tau}\right)\right]+\mathbb{E}_{\tilde{c}_{t}}\left[\sum_{t=(\tau+1)}^{\infty} \frac{\hat{\Pi}_{S F E}}{(1+r)^{t-\tau}}\right]
$$

with $\hat{\Pi}_{A P T}$ representing profits from sustained collusion at the level $\Delta_{\tau}, \hat{\Pi}_{d e v}$ being deviative profits and $\hat{\Pi}_{S F E}$ the profits at the non-cooperative equilibrium.

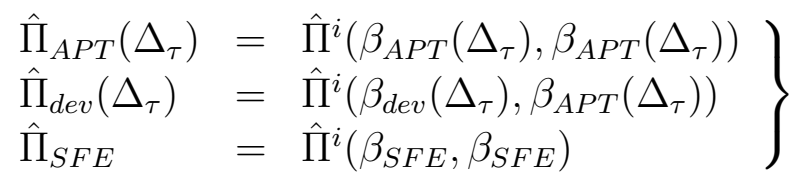

I am interested in $\Delta_{\tau}$ as the critical variable for sustained collusion and will treat $r$ as a parameter. Note that it is sufficient to analyse the constraint with respect to one critical value of $\Delta_{\tau}$ for the current period $\tau$ and $\Delta_{t}=\Delta_{\tau}$ for all future periods $t \geq \tau$. Let $\Delta_{I C}$ denote this critical value, such that the constraint (11) still holds. See (11) and note that only the left hand side of the inequality is affected by future increases of $\Delta_{t}$. So when $\Delta_{\tau}>\Delta_{I C},(11)$ is not verified, and considering future increases of $\Delta_{t}$ is meaningless because collusion already broke. When (11) is slack, considering $\Delta_{t}>\Delta_{\tau}$ does not harm the constraint for all $\Delta_{\tau} \leq \Delta_{\max }$, because this would only increase the left hand side. To resume this argument: assuming no future changes in $\Delta_{t}$ is the most critical scenario for the incentive constraint which implies that the constraint holds for all other scenarios as well. It is tempting to derive an analytical solution for this critical value $\Delta_{I C}$. Unfortunately, it seems impossible to solve the constraint explicitly. Nevertheless, the following section will show some analytical results from the overall behaviour of the inequality.

\section{Solving the Repeated Game}

The complexity of the incentive constraint lies not only in its functional form, but in the presence of two random variables. To gain analytical insights, I have to make some assumptions about the stochastic properties of cost and demand shocks. 
Assumption 1 The anticipated probability distribution of $\tilde{N}_{t}$ is independent of cost shocks and of time.

Assumption 2 The anticipated probability distribution function $f\left(c_{t}\right)$ is the same for all $t$ and $\mathbb{E}\left[\tilde{c}_{t}\right]=c_{\tau}$ for all $t \geq \tau$.

Assumption 1 is the less critical assumption: Independence of cost and demand shocks seems reasonable for the case of emission allowance prices and electricity consumption. The assumption of constant expected demand over time might as well be replaced by assuming a linear time trend, which would simply translate into a different discount factor. For the sake of simplicity, I did not consider a time trend here.

Assumption 2 is quite restrictive but inevitable in order to obtain analytical results. Numerical implementations might overcome this drawback in the future, but this is clearly beyond the scope of this paper.

The assumptions permit to treat constraint (11) in a much more convenient form. Expected profits with respect to demand shocks can be expressed as in (5); the expectation of profits with respect to cost shocks is obtained by integrating over all possible values of $c_{t} \in[\underline{c}, \bar{c}]$. Independence of time allows to sum up equivalent terms for future expected profits, which form a geometric sequence. The incentive constraint can now be specified as follows.

$$
\hat{\Pi}_{A P T}\left(\Delta_{\tau}\right)+\int_{\underline{c}}^{\bar{c}} f(c)\left(\frac{1}{r}\right) \hat{\Pi}_{A P T}\left(\Delta_{\tau}\right) d c \geq \hat{\Pi}_{d e v}\left(\Delta_{\tau}\right)+\int_{\underline{c}}^{\bar{c}} f(c)\left(\frac{1}{r}\right) \hat{\Pi}_{S F E} d c
$$

The left hand side denotes profits from sustained collusion. The right hand side represents a one-period profit from deviation plus the discounted profits from non-cooperation in the future. Both sides of the inequality show integrals over $c$, which, however, do not include the whole term: for the current period $\tau$ the realisation of costs is known, but demand is not. Firms therefore calculate with the actual cost parameter and expected profits with respect to demand. Future profits are uncertain with respect to cost and demand fluctuations. Expected profits with respect to both variables are discounted at the interest rate $r$. Note again that future changes in $\Delta_{t}$ would only increase profits from sustained collusion. Thus, using the current value $\Delta_{\tau}$ for the evaluation of future profits does not affect the validity of the incentive constraint.

Still, the constraint is not solvable for a specific critical value $\Delta_{I C}$. (For the interested reader: the explicit form of (11) can be obtained, using the definitions in (12), (1), (8), (10) and (3).) Nevertheless, one can learn a lot from this incentive constraint by analysing its overall behaviour. The results are summed up in the following theorem, which is proved in three successive claims. Figure 1 might serve as an illustration. 


\section{THEOREM 1}

For an arbitrary set of parameters $\left\{r, \gamma, c_{\tau}\right\}$, firms always prefer to transmit costs asymmetrically when they are at the one-shot equilibrium, for a continuous interval $\Delta_{\tau} \in\left[0, \Delta_{I C}\right]$ with $\Delta_{I C}>0$, but never beyond $\Delta_{I C}$.

Proof of THEOREM 1.

\section{Claim 1.}

For a given pair of parameters $(r, \gamma)$, there exists a unique value $\Delta_{I C} \in \mathbb{R}_{+}$, such that the incentive constraint (13) is verified at $\Delta_{I C}$ and not verified for all $\Delta_{\tau}>\Delta_{I C}$.

Proof. At $\Delta_{\tau}=0, \beta_{A P T}=\beta_{\text {dev }}=\beta_{S F E}$, thus the inequality (13) becomes an identity and the constraint is verified. I will now analyse how the inequality evolves when $\Delta_{\tau}$ increases.

First, consider the left hand side of (13), representing discounted profits of sustained collusion as a function of $\Delta_{\tau}$. We know from PROPERTY 2 that starting from the non-cooperative equilibrium $\beta_{S F E}$, a joint decrease of $\beta$ increases profits until $\beta=\beta_{\text {col }}$. Further decreases of $\beta$ then decrease joint profits. $\beta_{A P T}$ is decreasing in $\Delta_{\tau}$, therefore $\Pi_{A P T}$ increases with $\Delta_{\tau}$ until $\Delta_{\tau}=\Delta_{\max }$ and then decreases with $\Delta_{\tau}$. When $\Delta_{\tau}$ goes to infinity, $\beta_{A P T}$ approaches zero. With $\beta \rightarrow 0$, there is no supply and therefore there are no profits. Hence, $\Delta_{\tau} \rightarrow \infty$ implies $\Pi^{i}\left(\beta_{A P T}\left(\Delta_{\tau}\right), \beta_{A P T}\left(\Delta_{\tau}\right)\right) \rightarrow 0$; in words: profits from asymmetric price transmission approach zero as well. The same property is true for expected profits with respect to demand or cost fluctuations. Considering the left hand side of the inequality (13), we know that this is merely a sum of expected profits when both firms play $\beta_{A P T}$, hence this side of the inequality first increases, and then decreases with $\Delta_{\tau}$, finally approaching zero.

Now consider the right hand side of the inequality (13). The only term depending on $\Delta_{\tau}$ is the profit of deviation $\Pi_{d e v}$. Its derivative with respect to $\Delta_{\tau}$ is

$$
\frac{\partial \hat{\Pi}^{i}\left(\beta_{d e v}, \beta_{A P T}\right)}{\partial \Delta_{\tau}}=\underbrace{\frac{\partial \hat{\Pi}_{d e v}^{i}}{\partial \beta_{j}}}_{<0} \underbrace{\frac{\partial \beta_{A P T}}{\partial \Delta_{\tau}}}_{<0}+\underbrace{\frac{\partial \hat{\Pi}_{d e v}^{i}}{\partial \beta_{i}}}_{=0} \frac{\partial \beta_{d e v}}{\partial \Delta_{\tau}}
$$

The first summand is positive; profits always increase the more the rival withholds its capacity. The second summand is zero because the deviating firm plays its best response and due to Property $1, \partial \Pi^{i} / \partial \beta_{i}=0$ at the best response. Therefore, deviative profits increase continuously with higher $\Delta_{\tau}$. 
Finally, we know that (13) is verified at $\Delta=0$; that the left hand side of the inequality first increases, then decreases in $\Delta$, and that the right hand side increases continuously. Therefore, there exists a maximum value $\Delta_{I C} \geq 0$ where both sides of the inequality coincide and never beyond.

Q.E.D.

For an illustration, see figure 1.

\section{Claim 2.}

All firms weakly prefer coordination by asymmetric price transmission to the non-cooperative equilibrium. Asymmetric price transmission is strictly preferred in the neighbourhood of the non-cooperative equilibrium.

$$
\exists \check{\Delta}>0 \text {, such that (13) holds at } \Delta_{\tau}=\check{\Delta} \text {, and }\left[\Delta_{\tau}=\check{\Delta}\right] \succ\left[\Delta_{t}=0\right] \text {. }
$$

Note that Claim 2 implies $\Delta_{I C}>0$.

Proof. We know that (13) holds as an identity at $\Delta_{\tau}=0$. To hold for larger values of $\Delta_{\tau}$, the left hand side of the inequality has to follow a higher slope than the right hand side. This condition can be phrased as the 'Inequality of Derivatives':

$$
\frac{\partial}{\partial \Delta_{\tau}}\left[\hat{\Pi}_{A P T}\left(\Delta_{\tau}\right)+\int_{\underline{c}}^{\bar{c}} f(c)\left(\frac{1}{r}\right) \hat{\Pi}_{A P T}\left(\Delta_{\tau}\right) d c\right]>\frac{\partial}{\partial \Delta_{\tau}} \hat{\Pi}_{d e v}\left(\Delta_{\tau}\right) \mid \Delta_{\tau}=0 .
$$

A sufficient condition for (14) is

$$
\frac{\partial}{\partial \Delta_{\tau}} \hat{\Pi}_{A P T}\left(\Delta_{\tau}\right)=\frac{\partial}{\partial \Delta_{\tau}} \hat{\Pi}_{d e v}\left(\Delta_{\tau}\right) \quad \quad \mid \Delta_{\tau}=0
$$

and

$$
\frac{\partial}{\partial \Delta_{\tau}} \int_{\underline{c}}^{\bar{c}} f(c)\left(\frac{1}{r}\right) \hat{\Pi}_{A P T}\left(\Delta_{\tau}\right) d c>0 \quad \quad \mid \Delta_{\tau}=0
$$

These two conditions can be checked separately. Expressing (14.a) for firm $i$ with respect to strategies of firm $i$ and $j$ yields

$$
\underbrace{\frac{\partial \hat{\Pi}_{A P T}^{i}}{\partial \beta_{i}}}_{=0} \frac{\partial \beta_{A P T}}{\partial \Delta_{\tau}}+\frac{\partial \hat{\Pi}_{A P T}^{i}}{\partial \beta_{j}} \frac{\partial \beta_{A P T}}{\partial \Delta_{\tau}}=\underbrace{\frac{\partial \hat{\Pi}_{d e v}^{i}}{\partial \beta_{i}}}_{=0} \frac{\partial \beta_{d e v}}{\partial \Delta_{\tau}}+\frac{\partial \hat{\Pi}_{d e v}^{i}}{\partial \beta_{j}} \frac{\partial \beta_{A P T}}{\partial \Delta_{\tau}} \quad \Delta_{\tau}=0
$$


At $\Delta_{t}=0$, no fictive costs are priced in and every firm bids the equilibrium strategy: $\beta_{A P T}(0)=\beta_{d e v}(0)=\beta_{S F E}$. Because $\beta_{S F E}$ is the best response, the derivative of firm $i$ 's profit with respect to its own strategy is zero, no matter if it is willing to cooperate or not. As indicated above, the corresponding derivatives cancel. Moreover, all firms earn equilibrium profits: $\Pi_{A P T}(0)=\Pi_{\text {dev }}(0)=\Pi_{S F E}$. What remains is an equation of the derivatives of firm $i$ 's equilibrium profit with respect to firm $j$ 's strategy,

$$
\frac{\partial \hat{\Pi}_{S F E}^{i}}{\partial \beta_{j}} \frac{\partial \beta_{A P T}}{\partial \Delta_{\tau}}=\frac{\partial \hat{\Pi}_{S F E}^{i}}{\partial \beta_{j}} \frac{\partial \beta_{A P T}}{\partial \Delta_{\tau}} \quad \mid \Delta_{\tau}=0
$$

which is evidently true.

Now consider (14.b). This condition requires discounted expected future profits to have a strictly positive slope in $\Delta_{\tau}$. However, the very central aim of collusion by asymmetric price transmission is increasing profits by not transmitting downward cost shocks. Consider the profit function $\Pi^{i}\left(\beta_{i}, \beta_{j}\right)$ at an arbitrary realisation of $c$. We know that $\beta_{A P T}$ strictly decreases in $\Delta_{\tau}$ and from PROPOSITION 2 that profits strictly increase for a joint decrease of $\left(\beta_{i}, \beta_{j}\right)$ as long as $\left(\beta_{i}, \beta_{j}\right)>\left(\beta_{c o l}, \beta_{c o l}\right)$. Therefore $\Pi_{A P T}$ strictly increases with $\Delta_{\tau} \leq \Delta_{\max }$ and the same applies to the expected value of $\Pi_{A P T}$. Thus, (14.b) is true at $\Delta_{\tau}=0$, which implies that the inequality of derivatives holds. Q.E.D.

\section{Claim 3.}

The incentive constraint (13) is verified for all $\Delta_{\tau} \in\left[0, \Delta_{I C}\right]$.

Establishing the proof of CLAIM 3 requires some calculus, which can be found in the appendix. The following reasoning uses the result from the appendix.

Proof. Consider both sides of the inequality as functions of $\Delta_{\tau}$. One can establish CLAIM 3 by proving a single crossing property for profits of deviation and profits of collusion if $\Delta_{\tau}>0$. Figure 1 might serve as an illustration.

We know from the proof of CLAIM 2 that both sides of the inequality coincide at $\Delta=0$, and that the left hand side starts with higher slope. We know from PROPERTY 2, that the left hand side increases with $\Delta$ until $\Delta_{\max }$ and then decreases, finally approaching zero. On the contrary, we know from the proof of Claim 1 that the right hand side is continuously increasing in $\Delta$.

First, suppose that no intersection took place in the interval $\Delta \in\left[0, \Delta_{\max }\right]$. Thus, the left hand side still exceeds the right hand side at $\Delta_{\max }$. Because the left hand side is monotonically decreasing for all $\Delta>\Delta_{\max }$, and the right hand side is monotonically increasing, they will intersect exactly once: at $\Delta_{I C}$.

Now suppose there is an intersection within the interval $\left[0, \Delta_{\max }\right]$ at an arbitrary $\bar{\Delta}>0$. Indeed, one can prove concavity of both functions over this 
interval (the proof of concavity is in the appendix), therefore they can intersect maximally twice: one intersection is at 0 and one is at $\bar{\Delta}$. However, since no further intersection is possible when both functions are concave, the right hand side exceeds the left hand side at $\Delta_{\max }$. From this point on, the left hand side is decreasing, and the right hand side is increasing. Hence, no other intersection is possible for all $\Delta>\bar{\Delta}$. Therefore, $\bar{\Delta}$ is unique, and corresponds exactly to the definition of $\Delta_{I C}$ in CLAIM 1.

Q.E.D.

Claim 1, 2 and 3 together are equivalent to ThEOREM 1. The proof of THEOREM 1 therefore ends with the proof of CLAIM $3 . \quad$ Q.E.D.

\section{The range of collusive equilibria in numerical examples}

From a regulatory point of view, it would be interesting to know more about the level of 'fictive costs' which can be priced in before collusion breaks. Numerical examples show that these levels vary significantly with the price sensitivity of demand given by $\gamma$ and less remarkably with the level of the interest rate $r$. Higher values of each of the both parameters typically narrow the interval for collusion. The interest rate, however, mainly determines another important feature: whether optimal collusion will be reached or not. In terms of the model developed throughout this paper, this corresponds to the order of $\Delta_{I C}$ and $\Delta_{\max }$. If $\Delta_{I C}<\Delta_{\max }$, collusion breaks before the perfect cartel solution is reached; if $\Delta_{I C}>\Delta_{\max }$, continued fluctuations of the cost parameter might lead to the establishment of a quasi-monopoly of perfectly colluding firms. Both cases are possible and illustrated in the following figures.

Figure 1 shows a numerical example with fixed values for $c_{\tau}, \mathbb{E}\left[\tilde{N}^{2}\right], \gamma$ and $r$. The horizontal axis gives values of fictive costs $\Delta_{\tau}$ in proportion to $c$. The solid line represents discounted profits of sustained collusion ('left hand side') as a function of $\Delta_{\tau}$. It first coincides with, then exceeds the dashed line which represents profits of deviation (result of CLAIM 2), reaches its maximum at $\Delta_{\max }$, then decreases and intersects for the second and last time the profit of deviation function at $\Delta_{I C}$ (result of CLAIM 1). No intersection takes place between 0 and $\Delta_{I C}$ (result of CLAIM 3 ). In this case, the perfectly collusive solution $\left(\Delta=\Delta_{\max }\right)$ would be incentive feasible.

Figure 2 shows the same example as figure 1, but with a significantly higher interest rate (10 times higher than before). One can see, that the order of $\Delta_{I C}$ and $\Delta_{\max }$ is now inverted. 


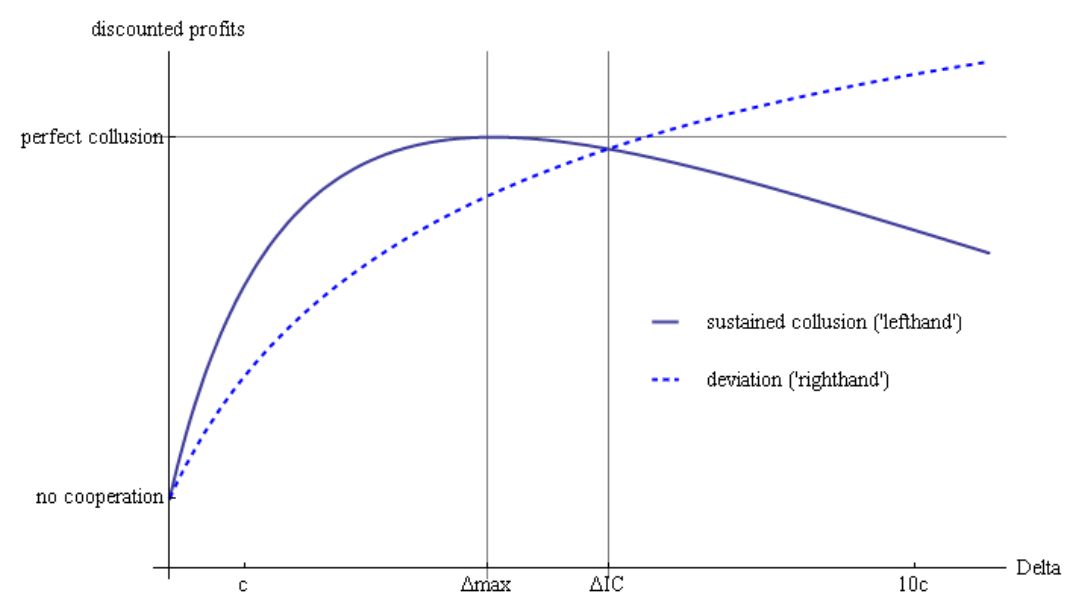

Figure 1: Both sides of the incentive constraint as functions of $\Delta$, low interest rate

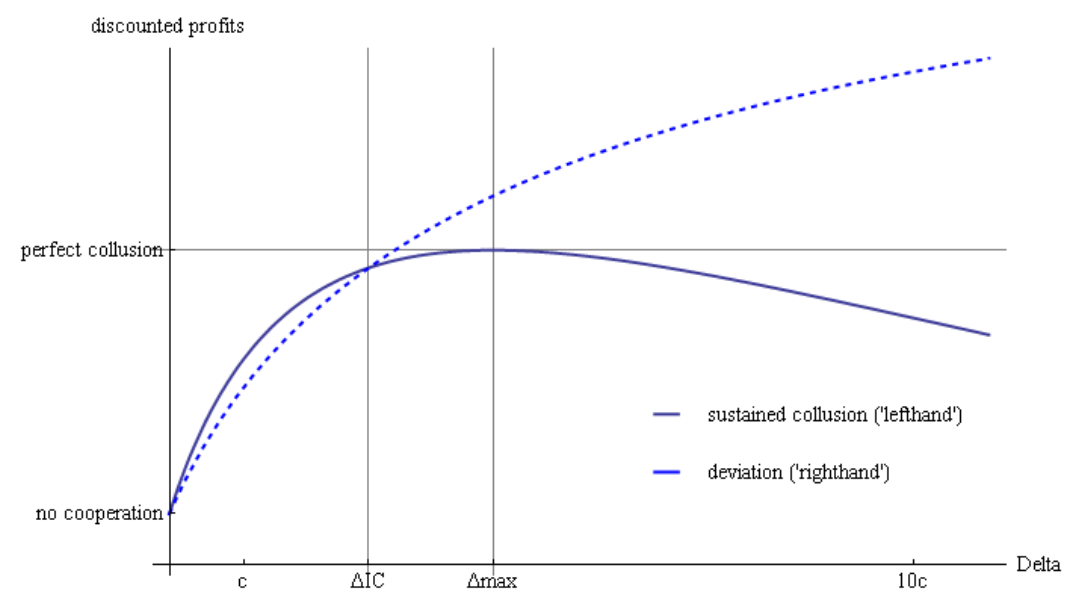

Figure 2: Both sides of the incentive constraint as functions of $\Delta$, high interest rate 


\section{Conclusion}

In this paper I have studied the strategic background of an asymmetric transmission of input prices at a power spot market. I discussed that joint profit maximisation at such power spot markets would yield potentially large extra profits but is hindered by incomplete information about rivals strategies and the lack of a focal point for collusive bidding. Asymmetric transmission of input price shocks, however, can be used as a coordinating mechanism to overcome the collusive dilemma of firms. Interpreting the input price shocks as a coordinating signal explains in an intuitive way why carbon prices qualify best as a collusive device. They have the necessary signalling quality: unambiguity with respect to time and level, continuous fluctuation and generality as a cost factor for each firm.

In the framework of a symmetric two-firm linear supply function equilibrium model, I established a theorem on the incentive feasibility of such coordination, which shows that the incentive constraint holds continuously for an interval of fictive costs $\left[0, \Delta_{I C}\right]$. This implies that firms always have an interest to depart jointly from the non-cooperative equilibrium when coordination is possible. Numerical examples show that even the monopoly solution might be incentivefeasible from the firms point of view, depending on the set of parameters. If the perfect cartel solution is reached without a break of collusion, we can assume firms to behave like a quasi-monopoly in the following. If tacit coordination looses incentive feasibility before perfect collusion is implemented, the lack of overt communication is likely to undermine the re-establishment of joint profit maximisation. Whether a perfect cartel solution is politically feasible at all is an open question.

The findings add to the literature on asymmetric price adjustment a model which applies even to the setting of a spot market with supply function bidding. This model provides the first attempt to explain the empirically proved phenomenon that EUA prices had an asymmetric effect on German power spot prices. It yields an explanation which is based on the informational structure of the market: the introduction of emissions trading provided an instrument for collusion which was lacking before. A first result for policy makers can be phrased as follows: distorting effects of a policy measure (the installation of emissions trading) might not only lie in the economic sphere of goods and money, but also occur through the informational structure for oligopolistic actors in neighbouring markets. Introduction of such measures should regularly be accompanied by enhanced anti-trust screening of industries involved.

Further research should to explore the theoretical findings of this article under a more realistic specification. Greater realism, however, requires a numerical implementation to relax the relevant assumptions. 


\section{A.1 Second order condition for the Best Response, and Proof of Proposition 1}

For the sufficient condition, consider the profit function given by (1). Its second derivative is

$$
\frac{\partial^{2} \Pi^{i}\left(\beta_{i}\right)}{\partial \beta_{i}^{2}}=\frac{6 \tilde{N}^{2}\left(\beta_{i}-\frac{c}{2} \beta_{i}^{2}\right)}{\left(\beta_{i}+\beta_{j}+\gamma\right)^{4}}-\frac{4 \tilde{N}^{2}\left(1-c \beta_{i}\right)}{\left(\beta_{i}+\beta_{j}+\gamma\right)^{3}}-\frac{c \tilde{N}^{2}}{\left(\beta_{i}+\beta_{j}+\gamma\right)^{2}} .
$$

Locally, at the best response the second derivative becomes

$$
\begin{aligned}
\frac{\partial^{2} \Pi^{i}\left(B R\left(\beta_{j}\right), \beta_{j}\right)}{\partial B R\left(\beta_{j}\right)^{2}}= & \frac{6 N^{2}\left(-\frac{c\left(\beta_{j}+\gamma\right)^{2}}{2\left(1+c\left(\beta_{j}+\gamma\right)\right)^{2}}+\frac{\beta_{j}+\gamma}{1+c\left(\beta_{j}+\gamma\right)}\right)}{\left(\beta_{j}+\gamma+\frac{\beta_{j}+\gamma}{1+c\left(\beta_{j}+\gamma\right)}\right)^{4}} \\
& -\left(\frac{4 N^{2}\left(1-\frac{c\left(\beta_{j}+\gamma\right)}{1+c\left(\beta_{j}+\gamma\right)}\right)}{\left(\beta_{j}+\gamma+\frac{\beta_{j}+\gamma}{1+c\left(\beta_{j}+\gamma\right)}\right)^{3}}+\frac{c N^{2}}{\left(\beta_{j}+\gamma+\frac{\beta_{j}+\gamma}{1+c\left(\beta_{j}+\gamma\right)}\right)^{2}}\right) \\
& =-\frac{N^{2}\left(1+c\left(\beta_{j}+\gamma\right)\right)^{4}}{\left(\beta_{j}+\gamma\right)^{3}\left(2+c\left(\beta_{j}+\gamma\right)\right)^{3}}<0 .
\end{aligned}
$$

Q.E.D.

\section{A.2 Second order condition for joint profit maximisation and proof of PROPOSITION 2}

The second order condition requires local concavity of joint profits for joint variations of $\beta$

$$
\begin{aligned}
\frac{\partial^{2} 2 \Pi\left(\beta_{c o l}, \beta_{c o l}\right)}{\partial \beta_{c o l}^{2}} & =-\frac{2 c N^{2}}{\left(\gamma+2 \beta_{c o l}\right)^{2}}-\frac{16 N^{2}\left(1-c \beta_{c o l}\right)}{\left(\gamma+2 \beta_{c o l}\right)^{3}}+\frac{48 N^{2}\left(\beta_{c o l}-\frac{c}{2} \beta_{c o l}^{2}\right)}{\left(\gamma+2 \beta_{c o l}\right)^{4}} \\
& =-\frac{2 c N^{2}}{\left(\gamma+\frac{2 \gamma}{2+c \gamma}\right)^{2}}-\frac{16 N^{2}\left(1-\frac{c \gamma}{2+c \gamma}\right)}{\left(\gamma+\frac{2 \gamma}{2+c \gamma}\right)^{3}}+\frac{48 N^{2}\left(\frac{\gamma}{2+c \gamma}-\frac{c \gamma^{2}}{2(2+c \gamma)^{2}}\right)}{\left(\gamma+\frac{2 \gamma}{2+c \gamma}\right)^{4}} \\
& =-\frac{2 N^{2}(2+c \gamma)^{4}}{\gamma^{3}(4+c \gamma)^{3}}<0
\end{aligned}
$$




\section{B Completion of the proof of CLAIM 3}

To complete the proof of CLAIM 3, it is sufficient to show concavity, (a) of profits of sustained collusion, and (b) of profits of deviation, each over the interval $\Delta \in\left[0, \Delta_{\max }\right]$. Showing this for an arbitrary value of $c$ implies concavity of the integral over all $c$, and therefore of the functions on either side of the incentive constraint (4).

\section{B.1 Proof of concavity of the 'left hand side'}

The 'left hand side' of the incentive constraint (4) represents discounted profits of sustained collusion. Both firms play the same strategy of asymmetric price transmission which I will denote $\beta$ for simplicity:

$$
\begin{gathered}
\beta_{i}=\beta_{j}=\beta_{A P T}(\Delta) \equiv \beta \\
\hat{\Pi}_{A P T}=\hat{\Pi}\left(\beta_{A P T}, \beta_{A P T}\right)=\hat{\Pi}(\beta)
\end{gathered}
$$

Note that $\beta$ is monotone decreasing in $\Delta$. One can therefore argue almost equivalently with either variable. The second derivative of collusive profits with respect to $\Delta$ is:

$$
\frac{\partial^{2} \hat{\Pi}(\beta)}{\partial \Delta^{2}}=\frac{\partial \hat{\Pi}}{\partial \beta} \frac{\partial^{2} \beta_{A P T}}{\partial \Delta^{2}}+\frac{\partial^{2} \hat{\Pi}}{\partial \beta^{2}}\left(\frac{\partial \beta_{A P T}}{\partial \Delta}\right)^{2}<0
$$

which I will have to prove negative. First, let us reduce the terms involved:

$$
\begin{aligned}
\frac{\partial \hat{\Pi}}{\partial \beta} & =\left(\frac{-4 \mathbb{E}\left[\tilde{N}^{2}\right]\left(\beta-\frac{c}{2} \beta^{2}\right)}{(\gamma+2 \beta)^{3}}\right)+\left(\frac{\mathbb{E}\left[\tilde{N}^{2}\right](1-c \beta)}{(\gamma+2 \beta)^{2}}\right) \\
& =\frac{\mathbb{E}\left[\tilde{N}^{2}\right]}{(\gamma+2 \beta)^{3}}\left(-4\left(\beta-\frac{c}{2} \beta^{2}\right)+(1-c \beta)(\gamma+2 \beta)\right) \\
& =\frac{\mathbb{E}\left[\tilde{N}^{2}\right]}{(\gamma+2 \beta)^{3}}(\gamma-\beta(2+c \gamma))
\end{aligned}
$$




$$
\begin{aligned}
& \frac{\partial^{2} \hat{\Pi}}{\partial \beta^{2}}=-6 \frac{\mathbb{E}\left[\tilde{N}^{2}\right](\gamma-\beta(2+c \gamma))}{(\gamma+2 \beta)^{4}}-\frac{\mathbb{E}\left[\tilde{N}^{2}\right](2+c \gamma)}{(\gamma+2 \beta)^{3}} \\
& =\frac{\mathbb{E}\left[\tilde{N}^{2}\right]}{(\gamma+2 \beta)^{3}}\left(\frac{-6(\gamma-\beta(2+c \gamma))}{\gamma+2 \beta}-(2+c \gamma)\right) \\
& =\frac{\mathbb{E}\left[\tilde{N}^{2}\right]}{(\gamma+2 \beta)^{3}}\left(\frac{4 \beta(2+c \gamma)-c \gamma^{2}-8 \gamma}{\gamma+2 \beta}\right) \\
& \beta^{\prime} \equiv \frac{\partial \beta_{A P T}}{\partial \Delta}=-\frac{\gamma}{(c+\Delta)^{2} \sqrt{\gamma^{2}+\frac{4 \gamma}{c+\Delta}}}<0 \\
& \left(\beta^{\prime}\right)^{2} \equiv\left(\frac{\partial \beta_{A P T}}{\partial \Delta}\right)^{2}=\frac{\gamma^{2}}{(c+\Delta)^{4}\left(\gamma^{2}+\frac{4 \gamma}{c+\Delta}\right)}>0 \\
& \beta^{\prime \prime} \equiv \frac{\partial^{2} \beta_{A P T}}{\partial \Delta^{2}}=-\frac{2 \gamma^{2}}{(c+\Delta)^{4}\left(\gamma^{2}+\frac{4 \gamma}{c+\Delta}\right)^{3 / 2}}+\frac{2 \gamma}{(c+\Delta)^{3} \sqrt{\gamma^{2}+\frac{4 \gamma}{c+\Delta}}} \\
& \frac{\left(\beta^{\prime}\right)^{2}}{\beta^{\prime \prime}}=\frac{\sqrt{\gamma^{2}+\frac{4 \gamma}{c+\Delta}}}{2 \gamma(c+\Delta)+6}>0 \\
& \Rightarrow \quad \beta^{\prime \prime}>0
\end{aligned}
$$

With the last result, one can equivalently express the convexity condition (B.1) by

$$
\begin{array}{cc}
\frac{\partial \hat{\Pi}}{\partial \beta}+\frac{\left(\beta^{\prime}\right)^{2}}{\beta^{\prime \prime}} \frac{\partial^{2} \hat{\Pi}}{\partial \beta^{2}} & <0 \\
\Leftrightarrow & <0 \\
\frac{\mathbb{E}\left[\tilde{N}^{2}\right]}{(\gamma+2 \beta)^{3}}(\gamma-\beta(2+c \gamma))+\frac{\left(\beta^{\prime}\right)^{2}}{\beta^{\prime \prime}} \frac{\mathbb{E}\left[\tilde{N}^{2}\right]}{(\gamma+2 \beta)^{3}}\left(\frac{4 \beta(2+c \gamma)-c \gamma^{2}-8 \gamma}{\gamma+2 \beta}\right) & <0 \\
\Leftrightarrow \quad \gamma-\beta(2+c \gamma)+\frac{\left(\beta^{\prime}\right)^{2}}{\beta^{\prime \prime}} \frac{4 \beta(2+c \gamma)-c \gamma^{2}-8 \gamma}{\gamma+2 \beta} & <0
\end{array}
$$


where I cancelled the common positive factor $\mathbb{E}\left[\tilde{N}^{2}\right] /(\gamma+2 \beta)^{3}$. Using equation (B.3) and the definition for $\beta=\beta_{A P T}$ in (8) yields

$$
\begin{aligned}
& \gamma-\beta(2+c \gamma)+\frac{4 \beta(2+c \gamma)-c \gamma^{2}-8 \gamma}{2 \gamma(c+\Delta)+6}<0 \\
& \Leftrightarrow \gamma \underbrace{-(2+c \gamma) \beta\left(\frac{2 \gamma(c+\Delta)+2}{2 \gamma(c+\Delta)+6}\right)}_{<0} \underbrace{-\frac{c \gamma^{2}+8 \gamma}{2 \gamma(c+\Delta)+6}}_{<0 ; \zeta \text { in } \Delta}<0
\end{aligned}
$$

The first summand is positive and constant, the two latter are negative, the last term is evidently negative and increasing in $\Delta$. To learn more about the behaviour of this condition, differentiate the second summand with respect to $\Delta$ :

$$
\begin{aligned}
& \frac{\partial}{\partial \Delta}\left[-(2+c \gamma) \beta\left(\frac{2 \gamma(c+\Delta)+2}{2 \gamma(c+\Delta)+6}\right)\right] \\
= & -(2+c \gamma)\left(\beta^{\prime} \frac{2 \gamma(c+\Delta)+2}{2 \gamma(c+\Delta)+6}+\beta \frac{8 \gamma}{(2 \gamma(c+\Delta)+6)^{2}}\right)
\end{aligned}
$$

Using the definitions in (8) and (B.2) gives

$$
\begin{aligned}
& -(2+c \gamma)\left(\frac{-\gamma(2 \gamma(c+\Delta)+2)}{(c+\Delta)^{2} \sqrt{\gamma^{2}+\frac{4 \gamma}{c+\Delta}}(2 \gamma(c+\Delta)+6)}+\frac{4 \gamma\left(\sqrt{\gamma^{2}+\frac{4 \gamma}{c+\Delta}}-\gamma\right)}{(2 \gamma(c+\Delta)+6)^{2}}\right) \\
& =-\frac{2+c \gamma}{2 \gamma(c+\Delta)+6}\left(\frac{-2 \gamma^{2}(c+\Delta)+2 \gamma}{(c+\Delta)^{2} \sqrt{\gamma^{2}+\frac{4 \gamma}{c+\Delta}}}+\frac{4 \gamma\left(\sqrt{\gamma^{2}+\frac{4 \gamma}{c+\Delta}}-\gamma\right)}{2 \gamma(c+\Delta)+6}\right) \\
& =\frac{-\gamma(2+c \gamma)}{2 \gamma(c+\Delta)+6}\left(\frac{-12-4 \gamma(c+\Delta)^{2} \sqrt{\gamma^{2}+\frac{4 \gamma}{c+\Delta}}}{(6+2 \gamma(c+\Delta))(c+\Delta)^{2} \sqrt{\gamma^{2}+\frac{4 \gamma}{c+\Delta}}}\right) \\
& =\left(\frac{\gamma(2+c \gamma)\left(12+4 \gamma(c+\Delta)^{2}\right) \sqrt{\gamma^{2}+\frac{4 \gamma}{c+\Delta}}}{(2 \gamma(c+\Delta)+6)^{2}(c+\Delta)^{2} \sqrt{\gamma^{2}+\frac{4 \gamma}{c+\Delta}}}\right)>0
\end{aligned}
$$


This shows that the term in (B.4) is monotonically increasing in $\Delta$. The term is negative over the whole interval $\Delta \in\left[0, \Delta_{\max }\right]$ if and only if it is negative at the upper bound $\Delta_{\max }$. Recall that at $\Delta=\Delta_{\max }$ both firms are at the perfectly collusive equilibrium, so due to PROPERTY 2, one has $\partial \Pi / \partial \beta=0$ and $\partial^{2} \Pi / \partial \beta^{2}<0$. Consider (B.1) and it becomes clear that the inequality holds at this point, hence, it holds in its reduced form (B.4) and therefore for the whole interval $\Delta \in\left[0, \Delta_{\max }\right]$.Q.E.D.

\section{B.2 Proof of concavity of the 'right hand side'}

The 'right-hand-side' of the incentive constraint (4) represents discounted profits of deviation from collusion. Firm $i$ plays the best response to firm $j$ 's collusive strategy of asymmetric price transmission:

$$
\left|\begin{array}{l}
\beta_{i}=\beta_{d e v} \equiv B R\left(\beta_{j}\right) \\
\beta_{j}=\beta_{A P T}(\Delta) \\
\hat{\Pi}^{i}=\hat{\Pi}_{d e v} \equiv \hat{\Pi}^{i}\left(\beta_{d e v}, \beta_{A P T}\right)
\end{array}\right|
$$

Note that $\beta_{A P T}$ is monotone decreasing in $\Delta$, and $0<B R^{\prime}<1$. $\beta_{i}$ and $\beta_{j}$ therefore vary with the same sign, but a different magnitude in $\Delta$. The second derivative of a deviating firm's profit with respect to $\Delta$ is:

$$
\frac{\partial^{2} \Pi_{d e v}^{i}(\Delta)}{\partial \Delta^{2}}=\frac{\partial \hat{\Pi}^{i}}{\partial \beta_{j}} \frac{\partial^{2} \beta_{j}}{\partial \Delta^{2}}+\left(\frac{\partial^{2} \hat{\Pi}^{i}}{\partial \beta_{j}^{2}}+\frac{\partial^{2} \hat{\Pi}^{i}}{\partial \beta_{j} \partial \beta_{i}} \frac{\partial B R}{\partial \beta_{j}}\right)\left(\frac{\partial \beta_{j}}{\partial \Delta}\right)^{2}<0
$$

which is to be proved negative. 
The involved terms have the following functional forms,

$$
\begin{aligned}
& \frac{\partial \hat{\Pi}^{i}}{\partial \beta_{j}}=-\frac{2 \mathbb{E}\left[\tilde{N}^{2}\right]\left(\beta_{i}-\frac{c \beta_{i}^{2}}{2}\right)}{\left(\beta_{i}+\beta_{j}+\gamma\right)^{3}} \\
& =-\frac{\mathbb{E}\left[\tilde{N}^{2}\right]}{\left(\beta_{i}+\beta_{j}+\gamma\right)^{3}}\left(2 B R\left(\beta_{j}\right)-c B R\left(\beta_{j}\right)^{2}\right) \\
& =-\frac{\mathbb{E}\left[\tilde{N}^{2}\right]}{\left(\beta_{i}+\beta_{j}+\gamma\right)^{3}}\left(2 \frac{\left(\gamma+\beta_{j}\right)}{1+c\left(\gamma+\beta_{j}\right)}-c\left(\frac{\left(\gamma+\beta_{j}\right)}{1+c\left(\gamma+\beta_{j}\right)}\right)^{2}\right) \\
& =-\frac{\mathbb{E}\left[\tilde{N}^{2}\right]}{\left(\beta_{i}+\beta_{j}+\gamma\right)^{3}}\left(\frac{\left(\gamma+\beta_{j}\right)\left(2+c\left(\gamma+\beta_{j}\right)\right)}{\left(1+c\left(\gamma+\beta_{j}\right)\right)^{2}}\right) \\
& \frac{\partial^{2} \hat{\Pi}^{i}}{\partial \beta_{j}^{2}}=\frac{6 \mathbb{E}\left[\tilde{N}^{2}\right]\left(\beta_{i}-\frac{c \beta_{i}^{2}}{2}\right)}{\left(\beta_{i}+\beta_{j}+\gamma\right)^{4}} \\
& =\frac{\mathbb{E}\left[\tilde{N}^{2}\right]}{\left(\beta_{i}+\beta_{j}+\gamma\right)^{3}}\left(\frac{6 B R\left(\beta_{j}\right)-3 c B R\left(\beta_{j}\right)^{2}}{B R\left(\beta_{j}\right)+\beta_{j}+\gamma}\right) \\
& =\frac{\mathbb{E}\left[\tilde{N}^{2}\right]}{\left(\beta_{i}+\beta_{j}+\gamma\right)^{3}}\left(\frac{6-3 c \frac{\left(\gamma+\beta_{j}\right)}{1+c\left(\gamma+\beta_{j}\right)}}{2+c\left(\beta_{j}+\gamma\right)}\right) \\
& =\frac{\mathbb{E}\left[\tilde{N}^{2}\right]}{\left(\beta_{i}+\beta_{j}+\gamma\right)^{3}}\left(\frac{6+3 c\left(\gamma+\beta_{j}\right)}{\left(2+c\left(\beta_{j}+\gamma\right)\right)\left(1+c\left(\gamma+\beta_{j}\right)\right)}\right) \\
& =\frac{\mathbb{E}\left[\tilde{N}^{2}\right]}{\left(\beta_{i}+\beta_{j}+\gamma\right)^{3}}\left(\frac{3}{1+c\left(\gamma+\beta_{j}\right)}\right)
\end{aligned}
$$




$$
\begin{aligned}
\frac{\partial^{2} \hat{\Pi}^{i}}{\partial \beta_{j} \partial \beta_{i}} & =\frac{6 \mathbb{E}\left[\tilde{N}^{2}\right]\left(\beta_{i}-\frac{c \beta_{i}^{2}}{2}\right)}{\left(\beta_{i}+\beta_{j}+\gamma\right)^{4}}-\frac{2 \mathbb{E}\left[\tilde{N}^{2}\right]\left(1-c \beta_{i}\right)}{\left(\beta_{i}+\beta_{j}+\gamma\right)^{3}} \\
& =\frac{\mathbb{E}\left[\tilde{N}^{2}\right]}{\left(\beta_{i}+\beta_{j}+\gamma\right)^{3}}\left(\frac{6 B R\left(\beta_{j}\right)-3 c B R\left(\beta_{j}\right)^{2}}{B R\left(\beta_{j}\right)+\beta_{j}+\gamma}-2\left(1-c B R\left(\beta_{j}\right)\right)\right) \\
& =\frac{\mathbb{E}\left[\tilde{N}^{2}\right]}{\left(\beta_{i}+\beta_{j}+\gamma\right)^{3}}\left(\frac{3}{1+c\left(\gamma+\beta_{j}\right)}-2\left(1-c \frac{\left(\gamma+\beta_{j}\right)}{1+c\left(\gamma+\beta_{j}\right)}\right)\right) \\
& =\frac{\mathbb{E}\left[\tilde{N}^{2}\right]}{\left(\beta_{i}+\beta_{j}+\gamma\right)^{3}}\left(\frac{3}{1+c\left(\gamma+\beta_{j}\right)}-\frac{2}{1+c\left(\gamma+\beta_{j}\right)}\right) \\
& =\frac{\mathbb{E}\left[\tilde{N}^{2}\right]}{\left(\beta_{i}+\beta_{j}+\gamma\right)^{3}}\left(\frac{1}{1+c\left(\gamma+\beta_{j}\right)}\right)
\end{aligned}
$$$$
>0
$$

So $\partial^{2} \hat{\Pi}^{i} / \partial \beta_{j} \partial \beta_{i}$ has a positive sign. Consider (B.5): since all factors multiplying $\partial^{2} \hat{\Pi}^{i} / \partial \beta_{j} \partial \beta_{i}$ are positive, assuming $B R^{\prime}=1$ is a stricter condition than the one in (B.5). To simplify calculations, I will assume $B R^{\prime}=1$ throughout the rest of this proof.

The stricter condition instead of (B.5) is

$$
\beta_{A P T}^{\prime \prime}\left(\frac{\partial \hat{\Pi}^{i}}{\partial \beta_{j}}\right)+\left(\beta_{A P T}^{\prime}\right)^{2}\left(\frac{\partial^{2} \hat{\Pi}^{i}}{\partial \beta_{j}^{2}}+\frac{\partial^{2} \hat{\Pi}^{i}}{\partial \beta_{j} \partial \beta_{i}}\right)<0
$$

which can be simplified by cancelling some common positive factors.

$$
\begin{array}{ll}
\Leftrightarrow \frac{\beta_{A P T}^{\prime \prime}}{\left(\beta_{A P T}^{\prime}\right)^{2}}\left(\frac{-\left(\gamma+\beta_{j}\right)\left(2+c\left(\gamma+\beta_{j}\right)\right)}{\left(1+c\left(\gamma+\beta_{j}\right)\right)^{2}}\right)+\left(\frac{3+1}{1+c\left(\gamma+\beta_{j}\right)}\right) & <0 \\
\Leftrightarrow-\frac{\beta_{A P T}^{\prime \prime}}{\left(\beta_{A P T}^{\prime}\right)^{2}}\left(\gamma+\beta_{j}\right)\left(2+c\left(\gamma+\beta_{j}\right)\right)+4\left(1+c\left(\gamma+\beta_{j}\right)\right) & <0
\end{array}
$$


and finally

$$
\frac{-(2 \gamma(c+\Delta)+6)\left(\gamma+\beta_{j}\right)\left(2+c\left(\gamma+\beta_{j}\right)\right)+4\left(1+c\left(\gamma+\beta_{j}\right)\right) \sqrt{\gamma^{2}+\frac{4 \gamma}{c+\Delta}}}{\sqrt{\gamma^{2}+\frac{4 \gamma}{c+\Delta}}}<0
$$

Replacing $\beta_{j}$ by $\beta_{A P T}$ and cancelling the square root in the denominator yields

$$
\begin{aligned}
& -(\gamma(c+\Delta)+3)\left(\gamma+\sqrt{\gamma^{2}+\frac{4 \gamma}{c+\Delta}}\right)\left(2+c\left(\frac{\gamma+\sqrt{\gamma^{2}+\frac{4 \gamma}{c+\Delta}}}{2}\right)\right) \\
& +4\left(1+c\left(\frac{\gamma+\sqrt{\gamma^{2}+\frac{4 \gamma}{c+\Delta}}}{2}\right)\right) \sqrt{\gamma^{2}+\frac{4 \gamma}{c+\Delta}} \\
& =2 \sqrt{\gamma^{2}+\frac{4 \gamma}{c+\Delta}}\left(2+c\left(\gamma+\sqrt{\gamma^{2}+\frac{4 \gamma}{c+\Delta}}\right)\right) \\
& -3\left(\gamma+\sqrt{\gamma^{2}+\frac{4 \gamma}{c+\Delta}}\right)\left(2+c\left(\frac{\gamma+\sqrt{\gamma^{2}+\frac{4 \gamma}{c+\Delta}}}{2}\right)\right) \\
& \underbrace{-\gamma(c+\Delta)\left(\gamma+\sqrt{\gamma^{2}+\frac{4 \gamma}{c+\Delta}}\right)\left(2+c\left(\frac{\gamma+\sqrt{\gamma^{2}+\frac{4 \gamma}{c+\Delta}}}{2}\right)\right)}_{\equiv K, K>0} \\
& =2 \sqrt{\gamma^{2}+\frac{4 \gamma}{c+\Delta}}\left(2+c\left(\gamma+\sqrt{\gamma^{2}+\frac{4 \gamma}{c+\Delta}}\right)\right) \\
& -3 \sqrt{\gamma^{2}+\frac{4 \gamma}{c+\Delta}}\left(2+c\left(\frac{\gamma+\sqrt{\gamma^{2}+\frac{4 \gamma}{c+\Delta}}}{2}\right)\right) \\
& -3 \gamma\left(2+c\left(\frac{\gamma+\sqrt{\gamma^{2}+\frac{4 \gamma}{c+\Delta}}}{2}\right)\right)-K
\end{aligned}
$$




$$
\begin{aligned}
& =\frac{1}{2} \sqrt{\gamma^{2}+\frac{4 \gamma}{(c+\Delta)}} c\left(\gamma+\sqrt{\gamma^{2}+\frac{4 \gamma}{c+\Delta}}\right)-2 \sqrt{\gamma^{2}+\frac{4 \gamma}{(c+\Delta)}} \\
& -3 \gamma\left(2+c\left(\frac{\gamma+\sqrt{\gamma^{2}+\frac{4 \gamma}{c+\Delta}}}{2}\right)\right)-K \\
& =\frac{1}{2} c \gamma \sqrt{\gamma^{2}+\frac{4 \gamma}{(c+\Delta)}}+\frac{1}{2} c\left(\gamma^{2}+\frac{4 \gamma}{c+\Delta}\right) \\
& -2 \sqrt{\gamma^{2}+\frac{4 \gamma}{(c+\Delta)}}-6 \gamma-\frac{3}{2} c \gamma\left(\gamma+\sqrt{\gamma^{2}+\frac{4 \gamma}{c+\Delta}}\right)-K \\
& =\frac{1}{2} c\left(\frac{4 \gamma}{c+\Delta}\right) \\
& -2 \sqrt{\gamma^{2}+\frac{4 \gamma}{(c+\Delta)}}-6 \gamma-c \gamma\left(\gamma+\sqrt{\gamma^{2}+\frac{4 \gamma}{c+\Delta}}\right)-K \\
& =\underbrace{2 \gamma(\underbrace{\frac{c}{c+\Delta}}_{\leq 1}-3)}_{<0}-2 \sqrt{\gamma^{2}+\frac{4 \gamma}{(c+\Delta)}}-c \gamma\left(\gamma+\sqrt{\gamma^{2}+\frac{4 \gamma}{c+\Delta}}\right)-K<0
\end{aligned}
$$

In the last term, all summands have a negative sign. However, this term is only a reduced form of the one in condition (B.6), which implies (B.5). This establishes concavity of deviative profits in $\Delta$ at an arbitrary level $c>0$, and therefore concavity of the right hand side of the incentive constraint (13). Q.E.D. 


\section{References}

[Baldick et al., 2004] Baldick, R., Grant, R., and Kahn, E. (2004). Theory and Application of Linear Supply Function Equilibrium in Electricity Markets. Journal of Regulatory Economics, 25(2).

[Bolle, 1992] Bolle, F. (1992). Supply function equilibria and the danger of tacit collusion. Energy Economics.

[Borenstein et al., 1997] Borenstein, S., Cameron, A., and Gilbert, R. (1997). Do Gasoline Prices Respond Asymmetrically to Crude Oil Price Changes? The Qarterly Journal of Economics, 112(1).

[Bundeskartellamt, 2006] Bundeskartellamt (2006). Sachstandspapier zur Vorbereitung der mündlichen Verhandlung in Sachen Emissionshandel und Strompreisbildung. Preliminary report for the hearing in the litigation on carbon- and electricity trading, Bundeskartellamt (German Federal Cartel Office).

[EEX, 2007] EEX, E. (2007). Introduction to Exchange Trading at EEX on Xetra and Eurex. Leipzig. Release 0012A.

[Green and Porter, 1984] Green, E. J. and Porter, R. H. (1984). Noncooperative Collusion under Imperfect Price Information. Econometrica, 52(1).

[Green, 1996] Green, R. (1996). Increasing Competition in the British Electricity Spot Market. The Journal of Industrial Economics, 44(2).

[Klemperer and Meyer, 1989] Klemperer, P. D. and Meyer, M. A. (1989). Supply Function Equilibria in Oligopoly under Uncertainty. Econometrica, 57(6).

[Lewis, 2001] Lewis, M. (2001). Asymmetric Price Adjustment and Consumer Search: An Examination of the Retail Gasoline Market. Working Paper CPC04-47Rev, Competition Policy Center - University of Berkeley California.

[Peltzman, 2000] Peltzman, S. (2000). Prices Rise Faster than They Fall. Journal of Political Economy, 108(3).

[Tirole, 1988] Tirole, J. (1988). The Theory of Industrial Organisation. MIT Press. Chapter 6.

[Turnbull, 1983] Turnbull, S. J. (1983). Choosing Duopoly Solutions by Consistent Conjectures and by Uncertainty. Economics Letters, 13. 
[Zachmann and von Hirschhausen, 2008] Zachmann, G. and von Hirschhausen, C. (2008). First Evidence of Asymmetric Cost Pass-through of EU Emission Allowances: Examining Wholesale Electricity Prices in Germany. Economics Letters. forthcoming, pre-published as DIW Working Paper No. 708, July 2007. 